\title{
IMPACT OF SOIL SALINITY ON DIVERSITY AND COMMUNITY OF SUGARCANE ENDOPHYTIC PLANT GROWTH PROMOTING BACTERIA (SACCHARUM OFFICINARUM L. VAR. CP48)
}

\author{
PIRHADI, M. ${ }^{1}$ - ENAYATIZAMIR, N. ${ }^{{ }^{*}}-$ MOTAMEDI, H. ${ }^{2}-$ SORKHEH, K. ${ }^{3}$ \\ ${ }^{1}$ Department of Soil Science, Faculty of Agriculture, Shahid Chamran University of Ahvaz \\ Ahvaz, Iran \\ ${ }^{2}$ Department of Biology, Faculty of Science, Shahid Chamran University of Ahvaz \\ Ahvaz, Iran \\ ${ }^{3}$ Department of Agronomy and Plant Breeding, Faculty of Agriculture, Shahid Chamran \\ University of Ahvaz \\ Ahvaz, Iran \\ *Corresponding author \\ e-mail: n.enayatzamir@scu.ac.ir \\ (Received 29 $9^{\text {th }}$ Aug 2017; accepted 24 $4^{\text {th }}$ Nov 2017)
}

\begin{abstract}
The aim of this study was to isolate and identify culturable bacterial endophytes from sugarcane grown in saline and non-saline soil and assay some plant growth-related traits and evaluate selective isolate potential to improve growth, yield and grain phosphorus uptake of wheat. Endophytic bacteria associated with sugarcane grown in saline and non-saline soil were isolated from roots, stems and leave and tested for their ability to fix nitrogen, indole acetic acid (IAA) production and dissolution of insoluble phosphorus. A total of 55 endophytic bacteria were isolated from leaves, stems, and roots of sugarcane from saline and nonsaline soil. The results revealed a prevalence of Bacillaceae, with Bacillus sp. being the most frequently isolated bacterium. Salinity had the effect on bacterial community structure with the higher diversity of root entophytic bacteria in saline soils. From the isolates, four strains were shown to produce IAA and 19 strains showed the ability to solubilize phosphate, but twelve isolates having the best characteristics tests were identified using 16S rRNA gene sequencing. From the isolates Pseudomonas sp. SugS_49 with more phosphorus dissolution ability selected for evaluation on wheat growth. Application of Pseudomonas sp. SugS_49 caused increased growth, grain yield and phosphorus uptake of wheat.
\end{abstract}

Keywords: biofertilizer, phosphorus dissolution, pseudomonas, Shannon index, wheat

\section{Introduction}

Endophytic bacteria are ubiquitous colonizers of the inner plant tissues, viz., roots, stems, leaves or seeds where they do not normally cause any substantial morphological changes and disease symptoms (Hallmann et al., 1997). It was traditionally thought that endophytic bacteria cause mild diseases in plants, but recent research has proved that these bacteria can improve plant growth and increase their resistance against plant pathogens (Berg, 2009). The most predominant and studied endophytes belong to three major phyla (Actinobacteria, Proteobacteria, and Firmicutes) and include members of Azoarcus (Krause et al., 2006), Acetobacter (Bertalan et al., 2009), Bacillus (Deng et al., 2011), Enterobacter (Taghavi et al., 2010), Pseudomonas (Taghavi et al., 2009), and Stenotrophomonas (Ryan et al., 2008). Endophytic and rhizospheric bacteria improve plant growth through several mechanisms. They can increase plant growth by dissolving insoluble phosphorus, producing hormones such as indole acetic acid (IAA) and amino cyclopropane carboxylate deaminase (ACC), antimicrobial agents such as antibiotics 
and siderophore, nitrogen fixation, and reducing environmental stresses. They have beneficial effects on their host by preventing the spread of disease through synthesizing new compounds and antifungal metabolites (Ryan et al., 2008). Application of PGPR that was auxin producer (Bacillus thuringiensis, Enterobacter asburiae, and Serratia marcescens) caused to enhance nutrient uptake, seedling and root growth in wheat (Selvakumar et al., 2008). Improvement of grain yield, phosphorus uptake, and tillers number in wheat was observed after using a mixture of phosphate solubilizing bacteria and organic fertilizer (Afzal and Bano, 2008). The recent study showed an increase of wheat root length, root fresh and dry weight due to inoculation of bacterial in hydroponic culture (Singh et al., 2017). Although agricultural practices that use high amounts of external inputs, such as inorganic fertilizers, pesticides, and other amendments, can overcome specific soil constraints to crop production, this has resulted in continuous environmental degradation, particularly of soil, vegetation and water resources, especially in the most intensively managed systems. Therefore, we should now use alternative fertilizers without affecting the environment to reach sustainable agriculture. A potential option to increase the growth and yield of plants and reduce the destructive impact of chemical fertilizers on the environment can be the application of plant growth promoting bacteria (Krause et al., 2006). Beneficial properties of endophytes in increasing yields of agricultural crops, controlling plant diseases or pests, and adapting plants against stress conditions can encourage their increased application in sustainable agriculture practice (Mei and Flinn, 2010).

Sugarcane (Saccharum officinarum) is one of the five strategic products in the world and is considered as one of the best converters of solar energy to biomass and sugar (Yadav and Solomon, 2006). Sugarcane has an important role in the agriculture tradition of Khuzestan. This industry developed in the region and produces more than half of the country's sugar. Numerous reports are available on isolation of PGPR and their effects on growth and yield of crops. However, no information exists on the isolation and identification of endophytic bacteria from sugarcane cultivated in Iran. On the other hand salinity of soil under sugarcane cultivation due to irrigation practices and application of chemical fertilizer is now being seriously issue. There have been relatively few studies that have analyzed the effects of different environmental variables on endophyte diversity. Therefore it is necessary to pay attention to the effect of soil salinity on the diversity of sugarcane endophytic bacteria. The present study was carried out to isolate endophytic bacteria from the healthy roots, stems and leave of Saccharum officinarum L. var. CP48 grown in saline and non-saline soils with this hypothesis that endophytic bacterial communities within Saccharum officinarum vary among different tissues of the plant and are affected by the salinity of the soil in which the plant is growing.

After evaluation of some traits related to plant growth promotion of isolated bacteria, the impact of a selected halo tolerant isolate with phosphate dissolution ability was investigated on wheat plant growth parameters. This study may be further used for subsequent researches of isolates effect on plant growth as biological fertilizer.

\section{Materials and methods}

\section{Sample preparation}

Healthy roots, stems and leaves of 20 plants of sugarcane (Saccharum officinarum L.) cultivar CP48 near one-year-old plant cultivated in clay loam soils of two fields (with salinity levels of around $1.5-5 \mathrm{dS} / \mathrm{m}$ ) in Debal-Khazaei agro-industrial unit located 
in Khuzestan province of Iran (latitude $31^{\circ} 05^{\prime}$; longitude $48^{\circ} 30^{\prime}$ ) were sampled in October 2015. Fields have been under sugarcane cultivation for more than four years and managed using typical conventional farming practices appropriate for the region. The plants were collected in plastic bags and stored at $4^{\circ} \mathrm{C}$ within $72 \mathrm{~h}$ of collection. The roots, stems, and leaves of each plant were washed with tap water (to remove their mud and adhering soil). Then tissues of each plant were separated into three parts and cut into $2-4 \mathrm{~cm}$ pieces. About $10 \mathrm{~g}$ of each organ were weighed and placed in separate plates. Subsequently, the plant tissues were immersed in $70 \%$ ethanol for $1 \mathrm{~min}$. They were then transferred into $2 \%$ sodium hypochlorite solution for $3 \mathrm{~min}$, and $70 \%$ ethanol for $30 \mathrm{~s}$. Finally, they were rinsed three to five times with sterile distilled water until they were completely free of disinfectants (Mendes et al., 2007). The disinfection steps were carried out under the laminar flow hoods.

\section{Isolation of culturable endophytic bacteria}

Disinfected plant organs were macerated separately in sterile physiologic saline $(0.7 \% \mathrm{NaCl})$ and serially diluted to $10^{-8} .50 \mu 1$ of $10^{-3}$ to $10^{-8}$ dilutions were spread on nutrient agar medium in triplicates and incubated at $28^{\circ} \mathrm{C}$ for $72 \mathrm{~h}$. The appeared colonies were differentiated on the basis of colony morphology such as shape, margin, color, elevation, texture, and size of colony and pigmentation, thereafter the number of colonies that were similar in appearance was counted. Thereafter the isolates were classified to genus level according to Bergey's Manual of Determinative Bacteriology according to their physiological and biochemical properties (Holt et al., 1994). Microbial diversity was assayed by Shannon's diversity index $\left(\mathrm{H}^{\prime}\right)$. When diversity indices are used in ecology, the types of interest are usually species, but they can also be other categories, such as genera, families, functional types or haplotypes. The Shannon diversity index $(H)$ of isolated bacteria from each tissue was calculated by Equation 1 . The proportion of isolate $i$ relative to the total number of isolates $\left(p_{i}\right)$ is calculated, and then multiplied by the natural logarithm of this proportion $\left(\ln p_{i}\right)$. Shannon's equitability (Evenness) was calculated by dividing $H$ by $H_{\max }$ (here $H_{\max }=\ln N$ ).

$$
H=-\sum_{\mathrm{i}=1}^{\mathrm{S}} \mathrm{Pi} * \ln \mathrm{Pi}, \mathrm{Pi}=\frac{\mathrm{ni}(\text { Sample) }}{\mathrm{N}(\text { (sum) }}
$$

where:

$\mathrm{H}=$ the Shannon diversity index

$\mathrm{n}_{\mathrm{i}}=$ number of the ith isolate

$\mathrm{N}=$ number of total isolates in the sample

$\mathrm{S}=$ numbers of isolates encountered

$\sum=$ sum from isolate 1 to isolate $\mathrm{S}$

\section{Screening for traits related to plant growth promotion}

Nitrogen fixation ability of isolates was tested on nitrogen-free Doberenier's medium (Döbereiner et al., 1972). About $7 \mu \mathrm{l}$ of an overnight culture of isolates (16-18 h) was inoculated (in triplicate) on nitrogen-free agar medium and incubated for two days at $30^{\circ} \mathrm{C}$. The developed bacterial colonies changed medium color to yellow and were considered as nitrogen-fixing species (Bashan et al., 1993; Olivares et al., 1996).

To test the ability of all the bacterial isolates in dissolving phosphate, the researchers used National Botanical Research Institutes Phosphate - Bromophenol blue (NBRIP- 
BPB) medium (Nautiyal, 1999) containing (g/l): glucose (10), $\mathrm{Ca}_{3}\left(\mathrm{PO}_{4}\right)_{2}$ (5), $\mathrm{MgCl}_{2} \cdot 6 \mathrm{H} 2 \mathrm{O}(5), \mathrm{MgSO}_{4} \cdot 7 \mathrm{HO}(0.25), \mathrm{KCl}(0.2)$ and $(\mathrm{NH} 4)_{2} \mathrm{SO}_{4}(0.1), \mathrm{BPB}(0.025)$, agar (15). About $10 \mu \mathrm{l}$ of the overnight culture of isolates, containing $10^{7}$ cells $\mathrm{mL}^{-1}$ was inoculated on NBRIP-BPB medium and was then incubated for 3 days at $30^{\circ} \mathrm{C}$. The bacteria's ability to solubilize insoluble phosphates calculated via the formula of halo zone diameter/colony diameter (Sarkar et al., 2012). To carry out the quantitative estimation of phosphate solubilization by isolates, Erlenmeyer flasks $(50 \mathrm{ml})$ were used. They contained $10 \mathrm{ml}$ of NBRIP broth medium inoculated with $1 \%(\mathrm{v} / \mathrm{v})$ of an overnight culture of each isolates containing around $10^{8} \mathrm{CFU} / \mathrm{ml}$. The researchers utilized the autoclaved uninoculated NBRIP medium as a control. The flasks were incubated for 5 days at $30^{\circ} \mathrm{C}$ on a shaker at $150 \mathrm{rpm}$. After 5 days, the $\mathrm{pH}$ of the medium was measured and the supernatants were collected by centrifugation for $15 \mathrm{~min}$ at $8000 \mathrm{rpm}$. In order to estimate the available phosphorus content of harvested supernatant, the vanado-molybdate colorimetric method was used in which the absorbance was measured at a wavelength of $420 \mathrm{~nm}$. Finally, a standard curve prepared from $\mathrm{KH}_{2} \mathrm{PO}_{4}$ was used to determine the phosphorus content of samples (Inui-Kishi et al., 2012). The ability of isolates in producing auxin was tested on LBT medium (LuriaBertani tryptophan containing: $0.5 \%$ glucose, $0.5 \%$ yeast extract, $0.5 \% \mathrm{NaCl}, 1 \%$ tryptone, $0.05 \%$ tryptophan and $2 \%$ agar). The bacterial isolates were streaked on LBT solid media. They were then covered with filter papers and were incubated at $30^{\circ} \mathrm{C}$ for 18-24 h. Subsequently, filter papers were removed and a few drops of (Salkowski reagent) were added to them. The isolates were found to produce auxin when the color of papers turned into pink (Bric et al., 1991). The best isolates (with regard to their ability in nitrogen fixation, phosphate solubilization, and IAA synthesis) were chosen to sequence and the results were compared to sequences of GenBank based on partial $16 \mathrm{~S}$ rRNA sequences. Bacterial DNA was extracted and purified following the instructions of the DNA extraction Kit (SinaClone). The quality of extracted DNA was determined by electrophoresis on $1 \%$ agarose gel. Polymerase chain reaction was carried out in a volume of $50 \mu \mathrm{l}$ consisting of $1 \mathrm{x}$ PCR buffer, $2.5 \mathrm{U} / \mu$ ITaq Polymerase (Fermentas), 0.2 $\mathrm{mM}$ of each dNTP, $2 \mathrm{mM}$ magnesium chloride, $10 \mathrm{pM}$ of each primer (Fermentas) and 10 ng DNA.

Primers FD1 (5'CCGAATTCGTCGACAACAGAGTTTGATCCTGGCTCAG3') and reverse primer

RP1

(5'CCCGGGATCCAAGCTTACGGTTACCTTGTTACGACTT3') were used for PCR (Weisburg et al., 1991). The amplification was initiated at $94^{\circ} \mathrm{C}$ for $5 \mathrm{~min}$, followed by 30 cycles each containing denaturation $\left(94^{\circ} \mathrm{C}, 1 \mathrm{~min}\right)$, annealing $\left(58^{\circ} \mathrm{C}, 40 \mathrm{~s}\right)$, elongation $\left(72^{\circ} \mathrm{C}, 150 \mathrm{~s}\right)$, and a final extension $\left(72^{\circ} \mathrm{C}, 10 \mathrm{~min}\right)$. Target amplification was confirmed by electrophoresis in $1 \%(\mathrm{w} / \mathrm{v})$ agarose containing DNA. Partial $16 \mathrm{~S}$ rRNA gene of selective isolates was sequenced (Macrogen, South Korea). 16S rRNA sequence of the isolate was compared with that of other microorganisms via BLAST (http://www.ncbi.nlm.nih.gov/BLAST/Blast.cgi). Based on the results of the database searches, sequences were aligned with representative bacterial sequences from the GenBank database by using ClustalX (Thompson et al., 1997). Distance matrices and phylogenetic trees were calculated by the Hesegawa-Kishino-Yano model and neighbor-joining (NJ) algorithms using the program MEGA (version 6) by bootstrap analysis of 1000 replications (Tamura et al., 2013). The partial 16S rDNA sequences of the representatives were deposited in GenBank. 


\section{Plant growth and phosphorus uptake by wheat}

Plant growth promotion was evaluated in wheat variety Chamran in a greenhouse, using soil collected from the research area of Agriculture Faculty of Shahid Chamran University of Ahvaz. The collected soil was air-dried and passed through $4 \mathrm{~mm}$ sieve. The soil chemical analysis showed the following results: Electrical conductivity = $3.2 \mathrm{dS} / \mathrm{m}, \mathrm{pH} 7.8$, organic matter $=0.52 \%$, available $\mathrm{P}=8(\mathrm{mg} / \mathrm{kg})$, available $\mathrm{K}=270$ $\mathrm{mg} / \mathrm{kg}$ and total nitrogen $=0.04 \%$ with clay loam soil texture. A greenhouse experiment consisted of a $2 \times 3$ factorial in complete randomized design with four replications was arranged. The factors included two levels of inoculation (B0 without inoculant and B1 with inoculant) and three levels of phosphorus fertilizer. The nitrogen fertilizer used 400 $\mathrm{kg} / \mathrm{ha}$ urea. Phosphorus from the source of triple superphosphate applied at three levels of $100 \mathrm{~kg} / \mathrm{ha}$ (P100), $50 \mathrm{~kg} / \mathrm{ha}$ (P50) and without phosphorus application (P0). The soil was completely mixed and irrigated by distilled water to field capacity (70\%). Seeds of wheat (Triticum aestivum) Chamran cultivar were surface sterilized in $10 \%$ sodium hypochlorite solution for $10 \mathrm{~min}$, then rinsed with sterilized distilled water and planted at about $2 \mathrm{~cm}$ soil depth. The seeds were planted in pots containing $4 \mathrm{~kg}$ of steam sterilized clay loam soil. An overnight culture of the isolate was diluted to $10^{6} \mathrm{CFU} / \mathrm{mL}$ and $1 \mathrm{~mL}$ of inoculum (isolate S-49) was applied under each seed. During the experiment chlorophyll index by spad was measured. At the end of experiment plant height, dry weight of root and grain yield was measured. The digested grain samples analyzed using spectrophotometer at $470 \mathrm{~nm}$ for the quantification of phosphorus (Jaiswal, 2004) and then phosphorus uptake by grain was calculated. The data was analyzed statistically via SAS version9.1. Mean comparisons were done using Duncan test at $5 \%$.

\section{Results}

A total of 55 endophytic bacteria were isolated from the sugarcane tissues (26 isolates from saline soil and 29 isolates from non-saline soil), from which $18.18 \%$ belonged to roots ( 8 isolates from saline soil and 2 isolates from non-saline soil), $38.18 \%$ to stems ( 7 isolates from saline soil and 14 isolates from non-saline soil) and $43.63 \%$ to leaves (11 isolates from saline soil and 13 isolates from non-saline soil). In comparing the Shannon diversity index value of bacterial endophytic communities at genus level based on the sampling soil salinity situation, diversity (Shannon's Index) and evenness of isolated bacteria from saline soil was $\mathrm{H}=1.95$ and $\mathrm{E}=0.6$, respectively, and those was recorded $\mathrm{H}=1.58$ and $\mathrm{E}=0.47$ for non-saline soil. The most commonly isolated bacteria were in the phylum Firmicutes, which included 15 isolates and 20 isolates belong to saline and non-saline soil, respectively and constituted $57 \%$ of the total isolates in the tissues of plant grown in saline soil and $68 \%$ of the total isolates in the tissues of plant grown in non-saline soil. Genera in phylum Firmicutes included Staphylococcus, Paenibacillus and Bacillus. Other phyla identified as Actinobacteria included Corynebacterium, Arthrobacter, Rhodococcus, Streptomyces, Rhodococcus, Arthrobacter and another phyla Proteobacteria included Enterobacter, Pseudomonas and Aureimonas. We found that higher diversity of isolated bacteria from sugarcane roots grown in saline soil than non-saline soil that indicated high severity of salt stress increases diversity in the bacterial communities (Table 1). 
Table 1. Number and Shannon diversity components of isolated bacteria from sugarcane in saline and non-saline soil

\begin{tabular}{c|c|c|c|c|c|c}
\hline \multicolumn{7}{c}{ Isolated bacteria from sugarcane root } \\
\hline \multirow{2}{*}{ Genus } & \multicolumn{2}{c|}{ Number } & \multicolumn{2}{c}{ Pi } & \multicolumn{2}{c}{ In Pi } \\
\cline { 2 - 7 } & Saline soil & Non-saline soil & Saline soil & Non-saline soil & Saline soil & Non-saline soil \\
\hline Enterobacter & 3 & - & 0.37 & - & -0.99 & - \\
Staphylococcus & 3 & - & 0.37 & - & -0.99 & - \\
Corynebacterium & 1 & - & 0.12 & - & -2.48 & - \\
Paenibacillus & 1 & - & 0.12 & - & -2.48 & - \\
Arthrobacter & - & 1 & - & 0.5 & - & -0.69 \\
Bacillus & - & 1 & - & 0.5 & - & -0.69 \\
\hline \multicolumn{7}{|c|}{ Isolated bacteria from sugarcane shoot } \\
\hline Bacillus & 3 & 7 & 0.43 & 0.5 & -0.84 & -0.69 \\
Corynebacterium & 3 & - & 0.43 & - & -0.84 & - \\
Pseudomonas & 1 & - & 0.14 & - & -1.96 & - \\
Rhodococcus & - & 2 & - & 0.14 & - & -1.96 \\
Enterobacter & - & 1 & - & 0.071 & - & -2.64 \\
Staphylococcus & - & 1 & - & 0.071 & - & -2.64 \\
Aureimonas & - & 1 & - & 0.071 & - & -2.64 \\
Paenibacillus & - & 1 & - & 0.071 & - & -2.64 \\
Streptomyces & - & 1 & - & 0.071 & - & -2.64 \\
\hline \multicolumn{7}{|c|}{ Isolated bacteria from sugarcane leaf } \\
\hline Bacillus & 6 & 9 & 0.54 & 0.69 & -0.61 & -0.37 \\
Staphylococcus & 2 & 1 & 0.18 & 0.07 & -1.71 & -2.65 \\
Rhodococcus & 1 & 2 & 0.09 & 0.15 & -2.4 & -1.89 \\
Arthrobacter & 1 & 1 & 0.09 & 0.07 & -2.4 & -2.65 \\
Enterobacter & 1 & - & 0.09 & - & -2.4 & - \\
\hline
\end{tabular}

Diversity of isolated bacteria from sugarcane shoots in saline soil were lower than nonsaline soil, but those data from sugarcane leave were recorded higher in saline soil. From 55 isolated bacteria almost $21.81 \%$ of them were grown on $\mathrm{N}$-free medium and changed the color of medium to yellow, which suggests that they were able to fix atmospheric nitrogen (Tables 2, 3, 4), while 41, 33 and $25 \%$ of the isolated bacteria from roots, stems, and leaves indicated nitrogen fixation ability, respectively. The isolates from the roots with the codes R-1, R-9, and R-10, which were identified as Enterobacter, Paenibacillus and Enterobacter respectively, had the ability to fix nitrogen. All the endophytic isolates were initially tested by an agar assay using NBRIP medium to observe their phosphate solubilizing activity. The screened bacteria could solubilize TCP on solid medium by creating clear halozones around the colony. In fact, they represented different degrees of solubilization, depending on the type of organism involved (Tables 2, 3, 4). A clear halo zone was formed around the colony by almost 7 , 7 and 5 entophytic bacteria isolated from roots, stems, and leaves, respectively. Isolate S-49, which was taken from stems and was identified as Pseudomonas, exhibited the highest phosphate solubilization index on NBRIP plates which was followed by S-14 and B-13 isolates identified as Bacillus. 


$$
-731-
$$

Table 2. The results of some growth-promoting assays of isolated bacteria from the root

\begin{tabular}{cccccc}
\hline Strain code & Genus & Source & N-fixation & P-solubility index (SI) & Auxin production \\
\hline R-1 & Enterobacter & Saline soil & $+^{1}$ & 0.125 & $+^{4}$ \\
R-2 & Arthrobacter & Non-saline soil & $-^{2}$ & - & -5 \\
R-3 & Bacillus & Non-saline soil & - & - & - \\
R-4 & Staphylococcus & Saline soil & $+^{3}$ & 0.285 & - \\
R-5 & Corynebacterium & Saline soil & - & 0.2 & - \\
R-6 & Staphylococcus & Saline soil & - & - & - \\
R-7 & Enterobacter & Saline soil & + & 0.27 & + \\
R-8 & Staphylococcus & Saline soil & - & 0.22 & - \\
R-9 & Paenibacillus & Saline soil & ++ & 0.14 & - \\
R-10 & Enterobacter & Saline soil & ++ & 0.2 & + \\
\hline
\end{tabular}

${ }^{1}$ Growth of bacterium on $\mathrm{N}$-free medium and change the colour of medium to yellow

${ }^{2}$ Lack of bacterium growth on $\mathrm{N}$-free medium

${ }^{3}$ Poor growth of bacterium on $\mathrm{N}$-free medium

${ }^{4}$ Auxin production ability by changing the paper colour to pink

${ }^{5}$ No colour change of paper

Table 3. The results of some growth-promoting assays of isolated bacteria from the stem

\begin{tabular}{cccccc}
\hline Strain code & Genus & Source & N-fixation & P-solubility index (SI) & Auxin production \\
\hline S-14 & Bacillus & Non-saline soil & - & 0.43 & - \\
S-18 & Bacillus & Saline soil & - & - & - \\
S-25 & Bacillus & Saline soil & - & - & - \\
S-27 & Bacillus & Non-saline soil & - & - & - \\
S-28 & Bacillus & Non-saline soil & - & - & - \\
S-29 & Rhodococcus & Non-saline soil & - & - & - \\
S-30 & Bacillus & Saline soil & - & - & - \\
S-33 & Enterobacter & Non-saline soil & + & 0.12 & - \\
S-36 & Corynebacterium & Saline soil & - & - & - \\
S-38 & Bacillus & Non-saline soil & - & - & - \\
S-40 & Staphylococcus & Non-saline soil & - & - & - \\
S-41 & Aureimonas & Non-saline soil & - & 0.25 & + \\
S-42 & Corynebacterium & Saline soil & - & 0.18 & - \\
S-43 & Paenibacillus & Non-saline soil & - & - & - \\
S-45 & Bacillus & Non-saline soil & - & - & - \\
S-46 & Bacillus & Non-saline soil & - & - & - \\
S-48 & Bacillus & Non-saline soil & - & - & - \\
S-49 & Pseudomonas & Saline soil & + & 0.75 & - \\
S-50 & Streptomyces & Non-saline soil & + & 0.21 & - \\
S-54 & Rhodococcus & Non-saline soil & - & 0.33 & - \\
S-59 & Corynebacterium & Saline soil & + & - & - \\
\hline \multicolumn{7}{c}{} & & &
\end{tabular}


Table 4. The results of some growth-promoting assays of isolated bacteria from leave

\begin{tabular}{cccccc}
\hline Strain code & Genus & Source & N-fixation & P-solubility index (SI) & Auxin production \\
\hline B-11 & Bacillus & Non-saline soil & - & - & - \\
B-12 & Bacillus & Saline soil & + & 0.36 & - \\
B-13 & Bacillus & Non-saline soil & - & 0.42 & - \\
B-15 & Staphylococcus & Saline soil & + & 0.25 & - \\
B-16 & Rhodococcus & Non-saline soil & - & - & - \\
B-17 & Bacillus & Saline soil & - & - & - \\
B-19 & Bacillus & Saline soil & - & - & - \\
B-20 & Bacillus & Non-saline soil & - & - & - \\
B-21 & Bacillus & Non-saline soil & - & - & - \\
B-22 & Bacillus & Non-saline soil & + & 0.15 & - \\
B-23 & Staphylococcus & Saline soil & - & 0.22 & - \\
B-24 & Bacillus & Saline soil & - & - & - \\
B-26 & Bacillus & Non-saline soil & - & - & - \\
B-34 & Bacillus & Non-saline soil & - & - & - \\
B-35 & Bacillus & Saline soil & - & - & - \\
B-37 & Rhodococcus & Saline soil & - & - & - \\
B-39 & Rhodococcus & Non-saline soil & - & - & - \\
B-47 & Bacillus & Saline soil & - & - & - \\
B-51 & Arthrobacter & Saline soil & - & - & - \\
B-52 & Pseudomonas & Saline soil & - & - & - \\
B-53 & Arthrobacter & Non-saline soil & - & - & - \\
B-55 & Staphylococcus & Non-saline soil & - & - & - \\
B-56 & Bacillus & Non-saline soil & - & - & - \\
B-57 & Bacillus & Non-saline soil & - & - & - \\
\hline \multicolumn{7}{c}{} & & & - & - \\
& & & - & - \\
\end{tabular}

The ability of all isolates in solubilizing phosphate was further evaluated in NBRIP liquid broth medium. In both liquid broth and agar assays (Table 5) consistent results were obtained in regard with solubilizing phosphate from calcium phosphate. Various amounts of phosphate solubilization, from 4.35 to $15.36 \mathrm{mg} \mathrm{L}^{-1}$, were reported. Isolate S-49 showed maximum phosphate solubilizing activity in NBRIP medium with consistency result in agar assay which was followed by isolates S-14 and B-13. In this study, a decrease of $\mathrm{pH}$ was observed in the supernatant of the bacterial incubations.

According to the results of auxin production test in Tables 2, 3 and 4 only three isolates from the root and one isolate from the stem showed auxin production ability by changing the paper color to pink. Isolate R-1 (Enterobacter) had a higher ability to produce auxin than the other strains. Phylogenetic tree of bacteria based on 16S rRNA genes are shown in Figure 1. Comparative analysis of 16S rRNA sequence could help to identify isolates 1(R-1), 2(R-4), 3(R-7), 4(R-9), 5(R-10), 6(S-41), 7(S-49), 8(S-50), 9(B-12), 10(B-13), 11(B-15) and 12(B-22) as Enterobacter cloacae, Staphylococcus hominis, Enterobacter cloacae, Paenibacillus lactis, Enterobacter cloacae, Aureimonas altamirensis, Pseudomonas sp., Streptomyces roseofulvus, Bacillus endophyticus, Bacillus pumilus, Staphylococcus gallinarum and Bacillus pumilus, respectively. The obtained 16S rRNA sequences were deposited in Gene Bank under accession No. KX262849, KX898441, KX262850, KX898442, KX262851, KX898446, KX262853, 


$$
-733-
$$

KX898447, KX898443, KX898444, KX898445 and KX262852 for each of the mentioned isolates.

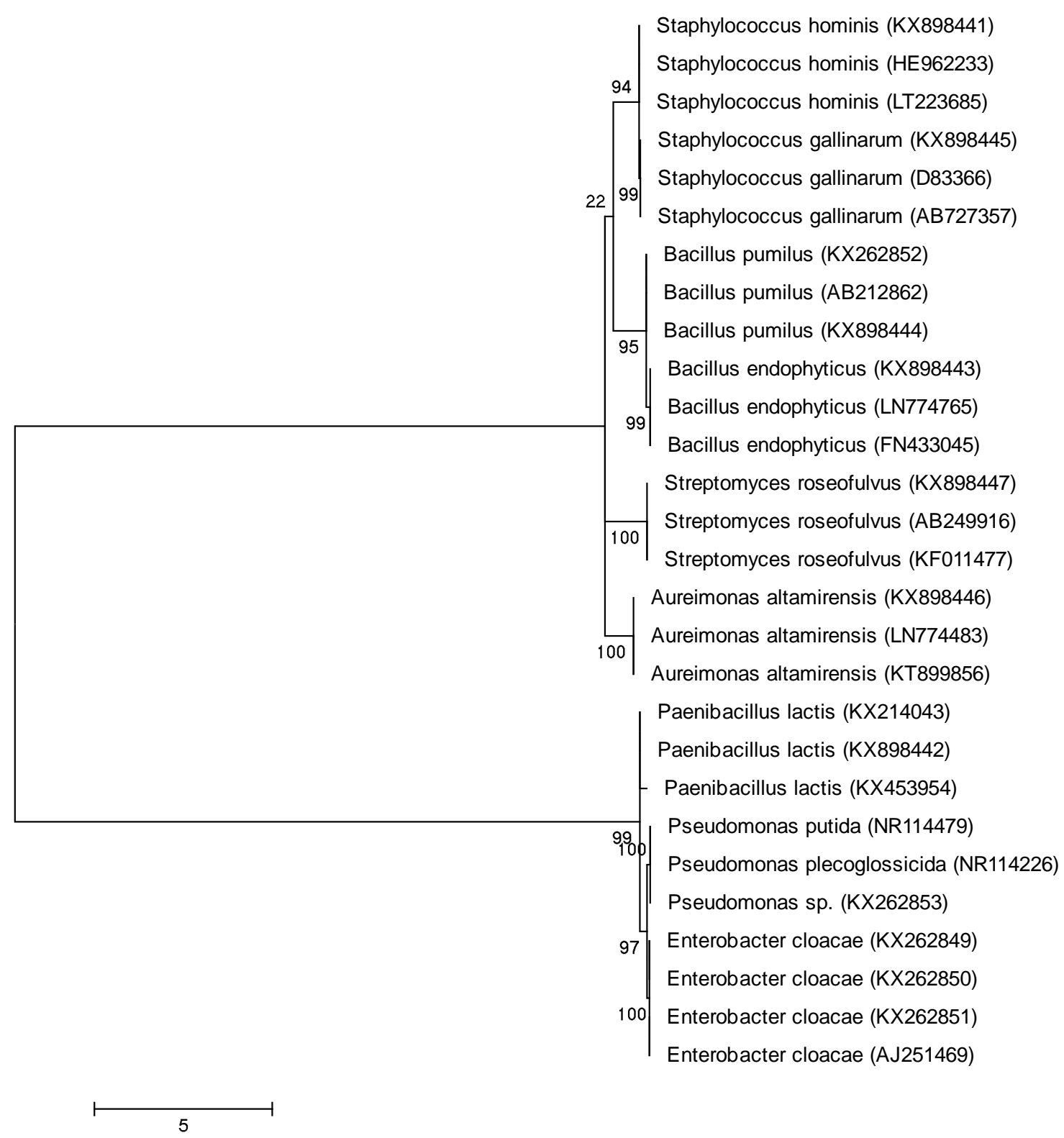

Figure 1. Phylogenetic tree of selected isolates based on 16S rRNA sequences

An overview of the effect of the selective isolate (Pseudomonas sp. sugS_49) according to insoluble phosphorus solubilization on some growth characteristic, grain yield and phosphorus uptake of wheat are presented in Table 6. The interaction effect of Pseudomonas sp. sugS_49 inoculation and phosphorus level was significant $(P \leq 0.05)$ on chlorophyll index. The maximum chlorophyll index was obtained by application of Pseudomonas sp. and the second level of phosphorus fertilizer $\left(\mathrm{P}_{50}\right)$. Significant synergetic effect on the dry weight of root and spike and also grain phosphorus uptake of wheat $(\mathrm{P}<0.05)$ was noticed due to combined application of phosphorus fertilizer and bacterial inoculation than phosphorus fertilizer application individually. 


$$
-734 \text { - }
$$

Significantly greater amount of noticed properties was obtained at Pseudomonas sp. treated soils with $100 \mathrm{~kg} / \mathrm{ha}$ of phosphorus application.

Table 5. $p H$ and phosphate solubilization in liquid media (Initial broth $p H=7.34$ )

\begin{tabular}{c|c|c|c|c}
\hline & Strain code & Genus & $\mathbf{p H}$ & $\mathbf{P}\left(\mathbf{m g} \mathbf{~ I}^{\mathbf{1}}\right)$ \\
\hline Control & - & - & 6.82 & 0.95 \\
\hline \multirow{6}{*}{ Root } & R-1 & Enterobacter & 5.85 & 10.03 \\
& R-4 & Staphylococcus & 6.15 & 13.01 \\
& R-5 & Corynebacterium & 4.44 & 10.12 \\
& R-7 & Enterobacter & 5.8 & 10.32 \\
& R-8 & Staphylococcus & 5.94 & 5.31 \\
& R-9 & Paenibacillus & 6.12 & 5.21 \\
& R-10 & Enterobacter & 5.98 & 11.96 \\
\hline \multirow{6}{*}{ Stem } & S-14 & Bacillus & 5.08 & 11.66 \\
& S-33 & Enterobacter & 5.2 & 9.33 \\
& S-41 & Aureimonas & 5.02 & 10.57 \\
& S-42 & Corynebacterium & 4.98 & 10.10 \\
& S-49 & Pseudomonas & 4.02 & 15.36 \\
& S-50 & Streptomyces & 5.5 & 9.31 \\
& S-54 & Rhodococcus & 5.1 & 9.64 \\
\hline \multirow{6}{*}{ Leave } & B-12 & Bacillus & 4.06 & 6.05 \\
& B-13 & Bacillus & 4.75 & 9.64 \\
& B-15 & Staphylococcus & 4.07 & 13.53 \\
& B-22 & Bacillus & 4.55 & 4.35 \\
& B-23 & Staphylococcus & 4.07 & 11.66 \\
\hline
\end{tabular}

Table 6. Mean comparison of treatments effect on some characteristics of wheat

\begin{tabular}{cccccc}
\hline Treatment & $\begin{array}{c}\text { Chlorophyll index Root dry weight } \\
\text { (Spad) }\end{array}$ & $\begin{array}{c}\text { Spike dry weigh } \\
\text { (g/pot) }\end{array}$ & $\begin{array}{c}\text { Grain yield } \\
\text { (g/pot) }\end{array}$ & $\begin{array}{c}\text { Phosphorus uptake } \\
\text { (mg/pot) }\end{array}$ \\
\hline $\mathrm{P}_{0} \mathrm{~B}_{0}$ & $41.47^{\mathrm{e}}$ & $0.51^{\mathrm{e}}$ & $7.11^{\mathrm{d}}$ & $5.37^{\mathrm{c}}$ & $16.07^{\mathrm{d}}$ \\
$\mathrm{P}_{50} \mathrm{~B}_{0}$ & $42.62^{\mathrm{d}}$ & $0.57^{\mathrm{d}}$ & $7.57^{\mathrm{c}}$ & $5.7^{\mathrm{c}}$ & $19.56^{\mathrm{c}}$ \\
$\mathrm{P}_{100} \mathrm{~B}_{0}$ & $42.52^{\mathrm{d}}$ & $0.62^{\mathrm{c}}$ & $7.19^{\mathrm{d}}$ & $6.25^{\mathrm{b}}$ & $19.36^{\mathrm{c}}$ \\
$\mathrm{P}_{0} \mathrm{~B}_{1}$ & $44.8^{\mathrm{b}}$ & $0.61^{\mathrm{c}}$ & $8.43^{\mathrm{b}}$ & $5.84^{\mathrm{c}}$ & $20.165^{\mathrm{c}}$ \\
$\mathrm{P}_{50} \mathrm{~B}_{1}$ & $45.7^{\mathrm{a}}$ & $0.69^{\mathrm{a}}$ & $9.08^{\mathrm{a}}$ & $6.67^{\mathrm{a}}$ & $28.653^{\mathrm{a}}$ \\
$\mathrm{P}_{100} \mathrm{~B}_{1}$ & $43.9^{\mathrm{c}}$ & $0.65^{\mathrm{b}}$ & $9.1^{\mathrm{a}}$ & $6.58^{\mathrm{a}}$ & $23.423^{\mathrm{b}}$ \\
\hline
\end{tabular}

Means followed by the same letters are not significantly different based on Duncan at $\alpha=5 \%$

\section{Discussion}

Diversity and evenness of isolated endophytic bacteria from sugarcane in saline soil were higher than non-saline soil indicated the high severity of salt stress increases diversity in the bacterial communities. According to earlier research (Lamizadeh et al., 2016), Shannon index of isolated bacteria from rhizosphere of sugarcane in saline soil was also higher than that in the non-saline soil. Bacterial density in the stems and leaves of plant grown in non-saline soil was more than in the roots. This distribution pattern 
was against the results of Mendes et al. (2007) which reported more isolates in roots than in stems and leaves. Bacillus (almost half of the isolated bacteria) was the most frequently observed genus in the roots, stems, and leaves. The result of the effectiveness of the surface sterilization protocol was also determined. The rinsed water of each sample showed no microbial growth on nutrient agar medium after incubation, indicating that the epiphytic microbes were completely removed by this surface sterilization procedures. In the present research, nitrogen fixing bacteria were mostly isolated from sugarcane roots and leaves. Similarly, Hongrittipun et al (2104) isolated high numbers of nitrogen-fixing bacteria from roots and leaves of rice. Most researches on sugarcane endophytic bacteria have focused on diazotrophicus bacteria among which there are important representatives such as Acetobacter diazotrophycus and species like Herbaspirillum (Muthukumarasamy et al., 1999). In India, research on sugarcane endophytic bacteria showed that diazotrophicus bacteria had less population than the other bacteria (Suman et al., 2001). In the same way, in Brazil, research on isolation and identification of endophytic bacteria from sugarcane showed that from 32 isolates, 14 isolates were from Enterobacteriaceae (Magnani et al., 2010). The ability of Enterobacter to fix nitrogen was also reported by Tam and Deep (Tam and Diep, 2014).

Isolate S-49, which was taken from stems and was identified as Pseudomonas, exhibited the highest phosphate solubilization index on NBRIP plates. This index was followed by S-14 and B-13 isolates, respectively and both were identified as Bacillus. According to previous studies Pseudomonas, Bacillus, Rhizobium, Micrococcus and Erwinia are reported as phosphate solubilizer bacteria (Rodriguez and Fraga, 1999). Pseudomonas and Bacillus have been screened inorganic phosphate solubilizing isolates from Pisumsativum L. plants (Oteino et al., 2015). Among the reported phosphate solubilizing bacteria, Bacillus and Pseudomonas are the most important bacteria (Chauhan et al., 2013; Sharma et al., 2013). An inverse relationship between $\mathrm{pH}$ and phosphorus solubility has been observed in the present research that confirmed by other researchers (Chen et al., 2006). The decreased $\mathrm{pH}$ of the cultures indicates that phosphorus has been dissolved and released in the medium (Asis et al., 2000). The consumption of glucose from the growth media and the production of organic acids can explain the resulting decrease in $\mathrm{pH}$. Results of auxin production by isolates are indicating the ability of Isolate R-1 (Enterobacter) to produce auxin than the other strains. Previous researches have shown that endophytic bacteria isolated from sugarcane also produce IAA (Chauhan et al., 2013; Tam and Diep, 2014). Most studies of sugarcane endophytes have focused on the diazotrophic bacteria (Olivares et al., 1996; Asis et al., 2000; Magnani et al., 2010). The Enterobacter genus was the most frequently found genus in the root. Enterobacter has been identified as endophytes of several plants such as Zea mays (Asis et al., 2000), soybean (Dalal and Kulkarni, 2013), and sugarcane (Tam and Diep, 2014). Pseudomonas aeruginosa, Pseudomonas fluorescens and Pseudomonas putida have been isolated from the stalk of sugarcane (Viswanathan et al., 2003). The Bacilli genera identified in sugarcane as endophytes: Bacillus pumillus was found to be associated with leaves. Chauhan et al. (2013) isolated Pseudomonas spp., Bacillus spp., Azospirillum spp. and Gluconacetobacter spp. from different varieties of sugarcane. The results reported here suggest that the population of sugarcane endophytes can vary depending on the plant organ analyzed. Further studies will be necessary to thoroughly analyze the endophytic population of sugarcane, including a collection of plants from different geographic origins and using the acetylene reduction assay to detect diazotrophicus bacteria. 
Application of Pseudomonas sp. SugS_49 alone and in combination with P fertilizer significantly increased growth, grain yield and phosphorus uptake of wheat. Similar results due to PGPR applications in wheat reported by Ponmurugan and Gopi (2006) and Afzal and Bano (2008). From this obtained results, it is clear that bio-fertilizer application was more effective to increase grain yield. The important finding was the measured properties in wheat under Pseudomonas sp. SugS_49 treatment without P fertilizer were almost more than those recorded in the second level of P, i.e. $\mathrm{P}_{50}$. Nutrient uptake enhances by inoculated plants may attribute to the production of plant growth regulators by the bacteria at the root interface, which stimulated root development and resulted in better absorption of water and nutrients from the soil (Abbasi et al., 2011). Increasing the bioavailability of $\mathrm{P}$ and $\mathrm{N}$ in soils with inoculation of PGPR which may lead to increased their uptake and plant growth, was reported by many researchers (Zaidi et al., 2003; Wani et al., 2007).

\section{Conclusion}

The microbial communication in salt-influenced soils may have a biotechnological potential, which illustrated a reserve for future use in biotechnological applications expecting they could be utilized as a part or the like of restoration or protection methods of saline conditions, but they can serve as model frameworks for investigating the relationships between assorted variety and activity at the soil level in selective/restricting circumstances. On completing this investigation, we are inspired by the wide diversity of microorganisms introduce in saline soils. Although the presence of endophytic microorganisms in roots and stems of various plants has been accounted previously, there are no providing details regarding the occurrence of endophytic microbes inside sugarcane in Iran. The endophytic bacterial community related with sugarcane harbors numerous genera with potential for plant advancement. On the basis of 16SrRNA gene, the greater part of the chose endophytic isolates acquired from sugarcane plants to belong to the genus Bacillus. Results of this investigation exhibit the presence of diazotrophic endophytic and phosphate solubilizing microorganisms inside the roots and leaves of Saccharum officinarum CP48. The utilization of phosphorus solubilizing Pseudomonas sp. SugS_49. in wheat cultivation has given an important choice to upgrading its yield and preserving inherent characteristic of some strains to which require impressive regard for creating biofertilizer for sugarcane cultivation in Iran for the future.

Acknowledgements. Authors would like to Thank Deputy of Research and Technology of Shahid Chamran University of Ahvaz for the support and Iran National Science Foundation for financial support under grant number of 93045179.

Conflict of Interest. The authors have declared that no competing interest exists.

\section{REFERENCES}

[1] Abbasi, M., Sharif, S., Kazmi, M., Sultan, T., Aslam, M. (2011): Isolation of plant growth promoting rhizobacteria from wheat rhizosphere and their effect on improving growth, yield and nutrient uptake of plants. - Plant Biosyst 145(1): 159-168. 
[2] Afzal, A., Bano, A. (2008): Rhizobium and phosphate solubilizing bacteria improve the yield and phosphorus uptake in wheat (Triticum aestivum L.) . - Int J Agric Biol 4: 454458.

[3] Asis, J. R., Constancio, A., Kubota, M., Ohta, H., Arima, Y., Chebotar, V. K., Tsuchiya, K., Akao, S.(2000): Isolation and partial characterization of endophytic diazotrophs associated with Japanese sugarcane cultivar. - Soil Sci Plant Nutr 46(3): 759-765.

[4] Bashan, Y., Holguin, G., Lifshitz, R. (1993): Isolation and Characterization of Plant Growth-Promoting Rhizobacteria. - In: Bernard, R., Glick, J., Thompson, E. (eds.) Methods in Plant Molecular Biology and Biotechnology. CRC Press, Boca Raton.

[5] Berg, G. (2009): Plant-microbe interactions promoting plant growth and health: perspectives for controlled use of microorganisms in agriculture. - Appl Microbiol Biotechnol 84(1): 11-18.

[6] Bertalan, M., Albano, R., Pádua, V., Rouws, L., Rojas, C. et al. (2009): Complete genome sequence of the sugarcane nitrogen-fixing endophyte Gluconacetobacter diazotrophicus Pal5. - BMC Genomics 10(1): 1-17.

[7] Bric, J. M., Bostock, R. M., Silverstone, S. E. (1991): Rapid in situ assay for indoleacetic acid production by bacteria immobilized on a nitrocellulose membrane. - Appl Environ Microbiol 57(2): 535-538.

[8] Chauhan, H., Bagyaraj, D. J., Sharma, A. (2013): Plant growth-promoting bacterial endophytes from sugarcane and their potential in promoting growth of the host under field conditions. - Exp Agri 49(1): 43-52.

[9] Chen, Y. P., Rekha, P. D., Arun, A. B., Shen, F. T., Lai, W. A., Young, C. C.(2006): Phosphate solubilizing bacteria from subtropical soil and their tricalcium phosphate solubilizing abilities. - Appl Soil Ecol 34(1): 33-41.

[10] Dalal, J., Kulkarni, N. (2013): Antagonistic and plant growth promoting potentials of indigenous endophytic bacteria of soybean (Glycine $\max (\mathrm{L})$ Merrill). - Curr Res Microbiol Biotechnol 1: 62-69.

[11] Deng, Y., Zhu, Y., Wang, P., Zhu, L., Zheng, J., Li, R., Ruan, L., Peng, D., Sun, M. (2011): Complete genome sequence of Bacillus subtilis BSn5, an endophytic bacterium of Amorphophallus konjac with antimicrobial activity for the plant pathogen Erwinia carotovora subsp. carotovora. - Bacteriol 193(8): 2070-2071.

[12] Döbereiner, J., Day, J. M., Dart, P. J. (1972): Nitrogenase activity in the rhizosphere of sugarcane and other tropical grasses. - Plant and Soil 37(1): 191-196.

[13] Hallmann, J., Quadt-Hallmann, A., Mahaffee, W. F., Kloepper, J. W. (1997): Endophytic bacteria in agricultural crops. - Can J Microbiol 43: 895-914.

[14] Holt, J. G., Krieg, N. R., Sneath, P. H. A., Staley, J. T., Willams, S. T. (1994): Bergey’s Manual of Determinative Bacteriology. - Williams \& Wilkins, Baltimore.

[15] Hongrittipun, P., Youpensuk, S., Rerkasem, B. (2014): Screening of nitrogen fixing endophytic bacteria in Oryza sativa L. - J Agric Sci 6(6): 66-74.

[16] Inui-Kishi, R. N., Kishi, L. T., Picchi, S. C., Barbosa, J. C., Lemos, M. T. O., Marcondes, J., Lemos, E. G. M. (2012): Phosphorus solubilizing and IAA production activities in plant growth promoting rhizobacteria from Brazilian soils under sugarcane cultivation. - $\mathbf{J}$ Eng Appl Sci 7(11): 1446-1454.

[17] Jaiswal, P. C. (2004): Soil, Plant, and Water Analyses. - Kalyani Publishers, Ludhiana.

[18] Krause, A., Ramakumar, A., Bartels, D., Battistoni, F., Bekel, T. et al. (2006): Complete genome of the mutualistic, $\mathrm{N}_{2}$-fixing grass endophyte Azoarcus sp. strain BH72. - Nat Biotechnol 24(11): 1-7.

[19] Lamizadeh, E., Enayatizamir, N., Motamedi, H. (2016): Isolation and identification of plant growth-promoting rhizobacteria (PGPR) from the rhizosphere of sugarcane in saline and non-saline soil. - Int J CurrMicrobiolAppl Sci 5(10): 1072-1083.

[20] Magnani, G. S., Didonet, C. M., Cruz, L. M., Picheth, C. F., Pedrosa, F. O., Souza, E. M. (2010): Diversity of endophytic bacteria in Brazilian sugarcane. - Genet Mol Res 9(1): 250-258. 
[21] Mei, C., Flinn, B. (2010): The use of beneficial microbial endophytes for plant biomass and stress tolerance improvement. - Recent Pat Biotechnol 4: 81-95.

[22] Mendes, R., Pizzirani-Kleiner, A. A., Araujo, W. L., Raaijmakers, J. M. (2007): Diversity of cultivated endophytic bacteria from sugarcane: Genetic and biochemical characterization of Burkholderia cepacia complex isolates. - Appl Environ Microbiol 73(22): 7259-7267.

[23] Muthukumarasamy, R., Revathi, G., Lakshminarasimhan, C. (1999): Influence of N fertilization of Acetobacter diazotrophicus and Herbaspirillum spp. from Indian sugarcane varieties. - Biol Fertil Soil 29: 157-164.

[24] Nautiyal, C. S. (1999): An efficient microbiological growth medium for screening phosphate solubilizing microorganism. - FEMS Microbiol Lett 170: 265-270.

[25] Olivares, F. L., Baldani, V. L. D., Reis, V. M., Baldani, J. I., Döbereiner, J. (1996): Occurrence of the endophytic diazotrophs Herbaspirillum spp. in roots, stems, and leaves, predominantly of Gramineae. - Biol Fertil Soil 21(3): 197-200.

[26] Oteino, N., Lally, R. D., Kiwanuka, S., Lloyd, A., Ryan, D., Germaine, K. J., Dowling, D. N. (2015): Plant growth promotion induced by phosphate solubilizing endophytic Pseudomonas isolates. - Front Microbiol 6(745): 1-9.

[27] Ponmurugan, P., Gopi, C. (2006): Distribution pattern and screening of phosphate solubilizing bacteria isolated from different food and forage crops. - J Agron. 5: 600-604.

[28] Rodriguez, H., Fraga, R. (1999): Phosphate solubilizing bacteria and their role in plant growth promotion. - Biotechnol Adv 17: 319-339.

[29] Ryan, R. P., Germaine, K., Franks, A., Ryan, D. J., Dowling, D. N. (2008): Bacterial endophytes: recent developments and applications. - FEMS Microbiol Lett 278: 19.

[30] Sarkar, A., Islam, T., Biswas, G. C., Alam, S., Hossain, M., Talukder, N. M. (2012): Screening for phosphate solubilizing bacteria inhabiting the rhizoplane of rice grown in acidic soil in Bangladesh. - Acta Microbiol 59: 199-213.

[31] Selvakumar, G., Kundu, S., Gupta, A. D., Shouche, Y. S., Gupta, H. S. (2008): Isolation and characterization of nonrhizobial plant growth promoting bacteria from nodules of Kudzu (Puerariathunbergiana) and their effect on wheat seedling growth. - Curr Microbiol 56: 134-139.

[32] Sharma, S. B., Sayyed, R. Z., Trivedi, M. H., Gobi, T. A. (2013): Phosphate solubilizing microbes: sustainable approach for managing phosphorus deficiency in agricultural soils. - Springer Plus 2(587): 1-14.

[33] Singh, D., Geat, N., Singh Rajawat, M. V., Prasanna, R., Saxena, A. K., Kaushik, R. (2017): Isolation and characterization of plant growth promoting endophytic diazotrophic bacteria from wheat genotypes and their influence on plant growth promotion. - Int $\mathbf{J}$ Curr Microbiol App Sci 6(4): 1533-1540.

[34] Suman, A., Shasany, A. K., Singh, M., Shahi, H. N., Gaur, A., Khanuja, S. P. S. (2001): Molecular assessment of diversity among endophytic diazotrophs isolated from subtropical Indian sugarcane. - World J Microbiol Biotechnol 17(1): 39-45.

[35] Taghavi, S., Garafola, C., Monchy, S., Newman, L., Hoffman, A., Weyens, N., Barac, T., Vangronsveld, J., Lelie, D. V. (2009): Genome survey and characterization of endophytic bacteria exhibiting a beneficial effect on growth and development of poplar trees. - Appl Environ Microbiol 75(3): 748-757.

[36] Taghavi, S., Lelie, D. V., Hoffman, A., Zhang, Y. B., Walla, M. D., Vangronsveld, J., Newman, L., Monchy, S. (2010): Genome sequence of the plant growth promoting endophytic bacterium Enterobacter sp. 638. - PLoS Genet 6(5): 1-15.

[37] Tam, H. M., Diep, C. N. (2014): Isolation, characterization and identification of endophytic bacteria in sugarcane (Saccharum spp. L.) cultivated on soils of the Dong Nai province, Southeast of Vietnam. - Am J Life Sci 2(6): 361-368.

[38] Tamura, K., Stecher, G., Peterson, D., Filipski, A., Kumar, S. (2013): MEGA6: Molecular Evolutionary Genetics Analysis version 6.0. - Mol Biol Evol 30(12): 27252729. 
[39] Thompson, J. D., Gibson,T. J., Plewniak, F., Jeanmougin, F., Higgens, D. G. (1997): The Clustal X windows interface: flexible strategies for multiple sequences alignment aided by quality analysis tools. - Nucleic Acids Res 25: 4876-882.

[40] Viswanathan, R., Sundar, A. R., Premkumari, S. M. (2003): Mycolytic effect of extracellular enzymes of antagonistic microbes to Colletotrichum falcatum, red rot pathogen of sugarcane. - World. J Microbiol Biotechnol 19(9): 953-959.

[41] Wani, P. A., Khan, M. S., Zaidi, A. (2007): Synergistic effects of the inoculation with nitrogen-fixing and phosphate-solubilizing rhizobacteria on the performance of fieldgrown chickpea. - J Plant Nutr Soil Sci 170: 283-287.

[42] Weisburg, W. G., Barns, S. M., Pelletier, D. A., Lane, D. J. (1991): 16S ribosomal DNA amplification for phylogenetic study. - J Bacteriol. 173(2): 697-703.

[43] Yadav, R. L., Solomon, S. (2006): Potential of developing sugarcane by-product based industries in India. - Sugar Tech 8(2): 104-111.

[44] Zaidi, A., Khan, M. S., Amil, M. (2003): Interactive effect of rhizotropic microorganisms on yield and nutrient uptake of chickpea (Cicer arietinum L.) . - Eur J Agron 19: 15-21. 